\title{
Stock Identification of Engraulis encrasicolus (Linnaeus, 1758) by Discriminant Function Analysis (DFA) of Morphometric Characters in The North of Atlantic and Mediterranean Moroccan Coasts
}

\author{
Mouna El qendouci ${ }^{1, *}\left(\mathbb{D}\right.$, Fatima Wariaghli ${ }^{1}(\mathbb{D})$, Mehria Saadaoui ${ }^{2}(\mathbb{D}$, Lobna \\ Boudaya $^{2}\left(\mathbb{D}\right.$, Lassad Neifar ${ }^{2}\left(\mathbb{D}\right.$, Abderrahim Sadak $^{1}\left(\mathbb{D}\right.$, Ahmed Yahyaoui $^{1}(\mathbb{D})$
}

\footnotetext{
${ }^{1}$ Mohammed V University in Rabat, Faculty of Sciences, Laboratory of Biodiversity, Ecology and Genome, Morocco. ${ }^{2}$ University of Sfax, Faculty of Sciences, Laboratory of Biodiversity and Aquatic Ecosystems, Tunisia.
}

\section{How to cite}

El qendouci, M., Wariaghli, F., Saadaoui, M., Boudaya, L., Neifar, L., Sadak, A., Yahyaoui, A. (2021). The Effect of Ploidy on Growth and Feeding Pattern of Diploid and Triploid Turbot Scophthalmus maximus Under Communal Rearing Condition. Turkish Journal of Fisheries and Aquatic Sciences, 21, 553-558. http://doi.org/10.4194/1303-2712-v21_11_03

\section{Article History}

Received 09 March 2021

Accepted 13 July 2021

First Online 14 July 2021

Corresponding Author

Tel.: +212650013355

E-mail: mouna.elqendouci@um5s.net.ma

\section{Keywords}

Engraulis encrasicolus

Stock identification

Morphometric characters

Discriminant analysis

\begin{abstract}
The European anchovy, Engraulis encrasicolus (Linnaeus, 1758) is a small pelagic fish found in the eastern Atlantic, the Mediterranean Sea and the Black Sea. Anchovy (E. encrasicolus) are among the important finfishes harvested in Moroccan coasts. The stock structure of European anchovy in NW Africa is not truly known (FAO, 2013). To effectively manage the anchovy fisheries, it is important to understand the anchovy stock structure. Therefore, discriminant function analysis (DFA) based on morphometric characters was conducted on a total of 204 adult anchovy specimens, seasonally collected by commercial fishing vessels from the region of Mehdia in the North Atlantic area and from the region of $\mathrm{M}^{\prime}$ diq in the Mediterranean coast during the year 2019. Body shape variation, which is often environmentally induced, may provide a good record population structuring. Our data were subjected to univariate statistics of variance (ANOVA) by using SPSS 20 software version. The morphometric characteristics show a separation of two stocks of Engraulis encrasicolus between the two localities. These findings will have major implications for anchovy fisheries management in Morocco.
\end{abstract}

\section{Introduction}

Long time ago, fishing has been a major source of food for humanity and a provider of employment and economic benefits. They have become an increasingly dynamic sector of the word of food industry, with many states striving to take advantage of the new opportunities that the sector presents in response to growing international demand for fish and fishery products. (FAO, 2007). In 2018, total global capture fisheries production reached the highest level ever recorded at 96.4 million tones, an increase of 5.4 percent from the average of the previous three years (FAO, 2020). The increase in 2018 was mostly driven by marine capture fisheries, whose production increased from 81.2 million tonnes in 2017 to 84.4 million tonnes in 2018, while catches from inland captures also recorded their highest-ever catches, at over 12 million tons (FAO, 2020).

Accurate stock determination is essential for achieving sustainable and productive fisheries (Kritzer \& Liu, 2014). Stock identification is a multidisciplinary field of fisheries science involving genetics, biometrics, and lifehistory studies (Ihssen et al., 1981; Templeman, 1982; Kumpf et al., 1987; ICES, 1996; Pawson and Jennings, 1996; Begg et al., 1999). Stock identification employs many tools such as genetics and morphometric to discriminate stocks (Cadrin, 2000). In traditional morphometry, the analysis of distant features obtained by image processing 
techniques is used for identification (Cavalcanti et al., 1999). Fisheries constitute an economic sector of prime importance in Morocco, with capture fisheries production at around 1.4 million tonnes in 2017 (INRH, 2017). Small pelagic fisheries occupy a very important place in the fishing sector in Morocco. It extends over the Moroccan continental shelf, Atlantic and Mediterranean and targets the main resources of small pelagic composed by sardines, anchovies, mackerel, horse mackerel and Sardinella. These species are characterized by significant horizontal and vertical migration in coastal waters (Fréon 2005) and go down in winter between 100 and $180 \mathrm{~m}$ deep, sometimes captured up to $400 \mathrm{~m}$. In Morocco, anchovy fisheries are very important and are one of the principal target species for commercial fisheries. This specie occupy crucial positions in upwelling regions where are an essential element of food chain (Bakun, 2006). Anchovy is a species distributed over a large area of distribution. It is spread throughout the eastern Atlantic from the coasts of the Norway north of Bergen $\left(62^{\circ} \mathrm{N}\right)$ to South Africa $\left(23^{\circ} \mathrm{S}\right)$. It is also found in the Baltic Sea, English Channel and North Sea. This species is also present throughout the Mediterranean Basin including the Black Sea and the Sea of Azov (Ba, 1989). Anchovy fishing in Morocco is known as sporadic and random fishing. Catches vary from one year to another, particularly because of the geographical distribution and behavior of schools that are not always accessible to seiners and the environmental variability that determines the abundance of this species. Morphometric characters are very useful to describe the population structure of fishes. However, in Morocco, this technique has not been applied in fisheries research to discriminate between fish stocks. The main objective of this study is to use for the first time the morphometric approach to discriminate the stock of Engraulis encrasicolus in the North of Atlantic and Mediterranean Moroccan coasts, in order to assess the status of this precious resource and contribute to develop a plan for better management.

\section{Materials and Methods}

\section{Sampling and Study Areas}

A total of 204 Engraulis encrasicolus specimens were randomly collected from the region of Mehdia in the North Atlantic area and from the region of $\mathrm{M}^{\prime}$ diq in the Mediterranean Sea by the purse-seiners during the year 2019 (Figure 1). Following the capture, samples were placed individually into plastic bags and were kept deep-frozen $\left(-20{ }^{\circ} \mathrm{C}\right)$ until transportation to the laboratory.

\section{Digitization of Samples}

Sampled specimens were cleansed in running water, drained and placed below a graduated ruler, which was used for calibrating the coordinates of the digital images. Each individual was labeled with a specific code for identification. Digital images of the left side of each specimen were captured by keeping the same distance between the camera lens and the individual of the sample. These images allow to provide a complete archive of body shape and repeat of the

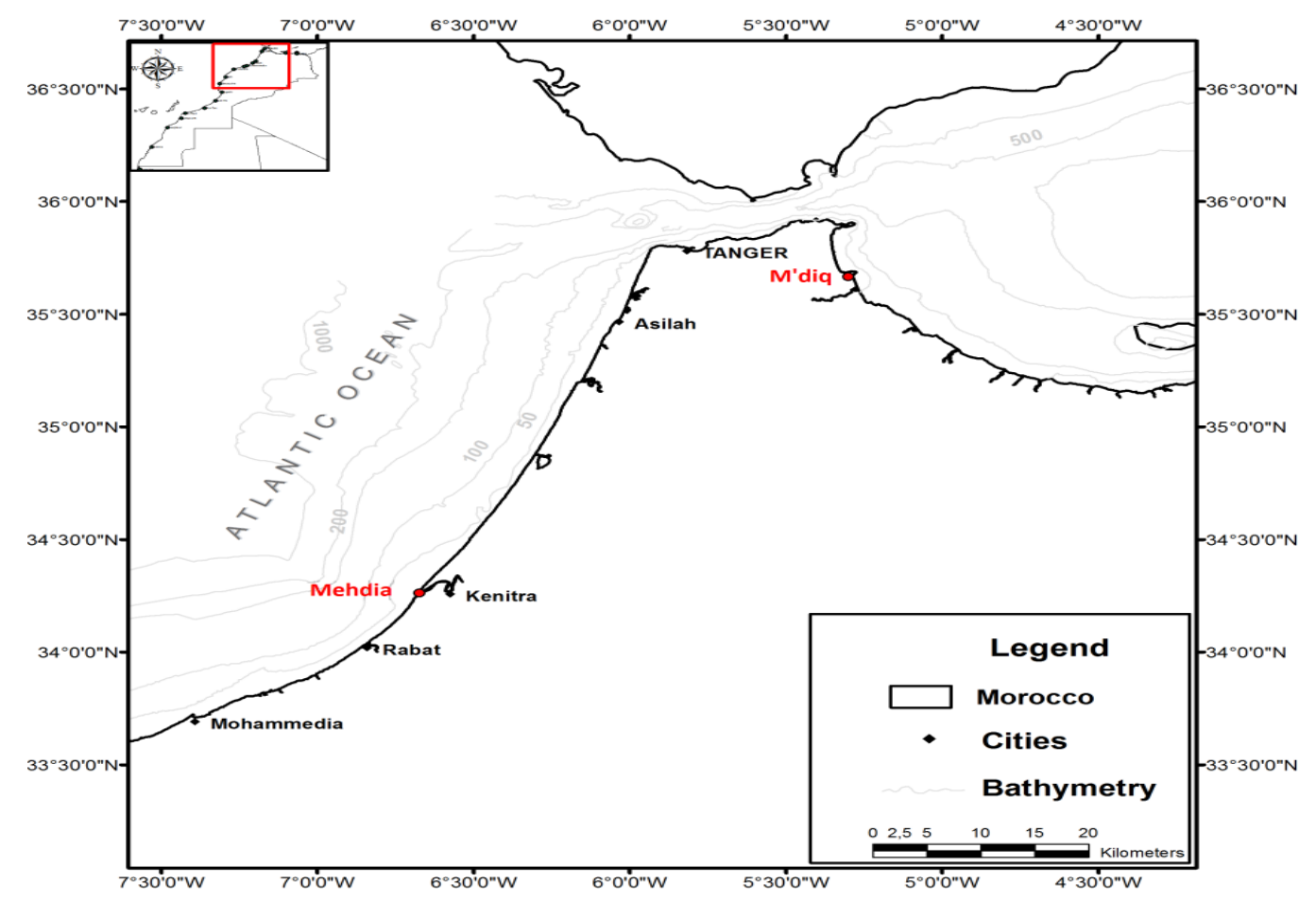

Figure 1. Sampling locations of anchovy Engraulis encrasicolus in the Atlantic and Mediterranean coast of Morocco. 
measurements when necessary (Cadrin and Friedland, 1999). Then fish were dissected for macroscopic examination of their gonads.

A total of 12 morphometric characters were measured in this study (Figure 2), including: Head length $(H L)$, Body height $(H)$, Pectoral length $(P e c L)$, Pelvic length (PeL), Dorsal length $(D L)$, Anal length $(A L)$, Fork length (FL), Total length (TL), Muzzle to dorsal fin (MD), muzzle to the head (MH), from Muzzle to Pectoral fin (MPec), from Muzzle to anal fin (MA). The extraction of distances from the digital images of specimens was conducted using a softwares: tpsutil, TpsDig2 v2.1 (Rohlf, 2006). All measurements were transferred to a spreadsheet file (Excel 2007).

\section{Multivariate Data Analysis}

Size dependent variation was corrected by adapting an allometric method as suggested by Elliott et al. (1995):

$$
M_{\text {adj }}=M\left(L_{s} / L_{0}\right)^{b}
$$

Where:

$M$ is the original measurement;

Madj is the size adjusted measurement

Lo the standard length of the fish

Ls the overall mean of standard length for all fish from all samples in each analysis, and b estimated for each character from the observed data as the slope of the regression of $\log \mathrm{M}$ on log Lo using all fish from each group. The results derived from the allometric method were confirmed by testing the significance of the correlation between the transformed variables and standard length (Turan, 1999).

Non-parametric analyses were performed to evaluate the differences of characters at the population level.

Chi-square analyses and Kruskall-Wallis test were used to analyse the effects between zones on the morphometric characters (Zar, 1984). Indeed, the Kruskall-Wallis tests the significance of the discrepancies observed in a multivariate analysis between two groups of individuals for a set of dependent variables (Everitt and Dunn, 1991). Discriminant analyses, based on Mahalanobis distances, were used to find the differences between zones and identify the morphometric characters. Statistical analyzes of morphometric data were performed using SPSS software version 20.

A non-metric multidimensional scaling method (nMDS) was applied to visually assess the differences in morphometric parameters between the studied zones. Similarity matrices were constructed based on BrayCurtis' similarity. This method assigns a non-dimensional location to each group and calculates the distances between groups. These analyses were performed using PRIMER ${ }^{\circledR}$-v6.

\section{Results}

Table 1 shows descriptive data for the sex ratio, mean length and standard deviation and length range of sampled specimens from the two studied zones (Mehdia and $M^{\prime}$ diq). Mean values are given with standard deviation ( \pm ). HL, head length; $H$, body height; PecL,

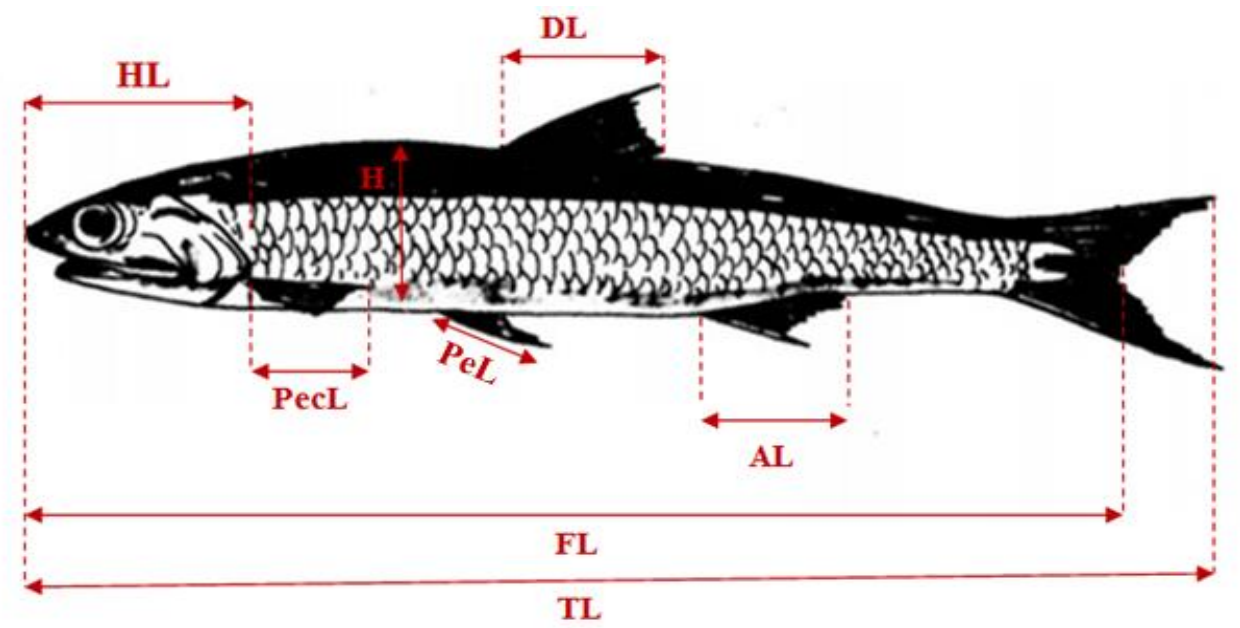

Figure 2. Morphometric variables measured on the body of Engraulis encrasicolus. TL, total length; FL, fork length; $\mathrm{HL}$, head length; $H$, body height; PeL pelvic length; PecL, pectoral length; $A L$, anal length; $D L$, dorsal length.

Table 1. Descriptive data of Engraulis encrasicolus in the study areas, with sample size (N), range, mean and standard deviation (SD) of standard length (SL) and total weight.

\begin{tabular}{lcccccc}
\hline Sample & $\mathrm{N}$ & Male & Female & SL range $(\mathrm{cm})$ & Mean SL $(\mathrm{cm} \pm$ SD) & Total weight $(\mathrm{g})$ \\
\hline M'diq & 84 & 28 & 56 & $10.86-14.92$ & $12.81 \pm 0.94$ & $22.01 \pm 4.72$ \\
Mehdia & 120 & 65 & 55 & $8.85-13.84$ & $11.69 \pm 1.18$ & $17.40 \pm 4.89$ \\
\hline
\end{tabular}


pectoral length; PeL pelvic length; $D L$, dorsal length; $A L$, anal length; $F L$, fork length; $T L$, total length; $M D$, from muzzle to dorsal fin; $\mathrm{MH}$, from muzzle to head; MPec, from muzzle to pectoral fin; $M A$, from muzzle to anal fin.

*Level of significance with $\mathrm{P}<0.05$.

$* *$ Level of significance with $\mathrm{P}<0.01$.

Among the 12 morphometric characters measured, we used 10 characters for the differentiation of the samples $(\mathrm{P}<0.05) \quad($ Table 2$)$. A multivariate discriminant analysis used to separate the anchovies between the studied zones according to the morphometric characteristics showed that the first discriminant function explains $100 \%$ of the variance (eigenvalue $=0.312$ ). Wilks's Lambda estimate shows a highly significant differentiation between the two groups (Wilks'lambda $=0.762 ;$ Chi-square $=54.364$; d.d.I $\left.=2 ; F_{31.235} ; \mathrm{P}<0.001\right)$.

Fish are classified correctly according to the two component communities, with an accuracy of $71.9 \%$ (Table 3). Based on the Mahalanobis distance, each morphometric character shows great importance in discriminating between groups. Indeed, the 10 characters measured being the most important characters for the differentiation of the samples are more important in the samples from Mehdia (Table 3).

Based on the morphometric characters, an nMDS analysis shows a distinction of the two groups, the first group formed mainly by the anchovy of M'diq and the other group formed by the anchovy collected at Mehdia (Figure 3).

\section{Discussion}

The reliability of morphometric characters in the delimitation of anchovy stocks has already been demonstrated by several works. However, no studies used this approach for the purpose of stock discrimination of $E$. encrasicolus in Morocco.
The results of the discriminant analysis used to separate anchovies from the two localities according to morphometric characters. This study shows a distinction between two different groups. One group formed by specimens from the M'diq area and the other group contains mainly Mehdia specimens. The results obtained show that there is a significant difference between the 10 morphometric characters measured. These morphological differences appear to be related only to the variation in body shape and not to size effects. The latter are eliminated by the allometric transformation. The major causes of morphological differences are difficult to understand, due to a complex understanding of the interactions between phenotypic expression, environmental influence and ontogeny (Cadrin and Friedland, 1999). However, the primordial role of environmental conditions, such as physicochemical and hydrological characteristics as well as predator density, in the determination of morphological variation has been demonstrated by several works (Murta, 2000; Langerhans et al, 2003; Moussa et al., 2005; Costa and Cataudella, 2007; Kristoffersen and Magoulas, 2008; Erdoğan et al., 2009). The M'diq area is influenced by currents coming from the Atlantic via the Strait of Gibraltar. Indeed, the Atlantic surface water creates a thermohaline front that generates two quasi-permanent anticyclonic eddies in the western and eastern regions of the Alboran Sea. The two interacting water masses cause deep water upwellings and significant hydrodynamics (La Violette, 1984). Whereas, in the northern zone of Morocco (33$36^{\circ} \mathrm{N}$ ), upwelling is weak because the wind is weak in this zone and the orientation of the coastline is unfavorable to generate strong upwelling (Benazzouz, 2014). This parameter could have an influence on fish swimming activity (Costa and Cataudella, 2007) and consequently on the general morphology of the body (Taylor and McPhail, 1985), as specimens from the M'diq

Table 2. Comparisons of morphometric characters of Engraulis encrasicolus from M'diq and Mehdia areas, Morocco.

\begin{tabular}{|c|c|c|c|c|}
\hline Morphometric characters & M'diq & Mehdia & Kruskal-Wallis & $P$-value \\
\hline $\mathrm{hl}$ & $3.11 \pm 0.23$ & $2.80 \pm 0.29$ & 23.79 & $0.000^{* *}$ \\
\hline $\mathrm{H}$ & $2.35 \pm 0.19$ & $2.09 \pm 0.23$ & 25.36 & $0.000^{* *}$ \\
\hline PecL & $1.45 \pm 0.13$ & $1.37 \pm 0.19$ & 41.41 & $0.000^{* *}$ \\
\hline PeL & $1.05 \pm 0.18$ & $0.97 \pm 0.13$ & 7.19 & $0.007^{* *}$ \\
\hline DL & $1.66 \pm 0.18$ & $1.49 \pm 0.19$ & 36.01 & $0.000^{* *}$ \\
\hline al & $1.95 \pm 0.18$ & $1.83 \pm 0.18$ & 36.48 & $0.000^{* *}$ \\
\hline $\mathrm{FI}$ & $13.81 \pm 1.06$ & $12.67 \pm 1.29$ & 0.19 & $0.006^{* *}$ \\
\hline TL & $14.79 \pm 1.08$ & $13.59 \pm 1.33$ & 40.70 & $0.000^{* *}$ \\
\hline $\mathrm{mD}$ & $6.47 \pm 0.50$ & $5.98 \pm 0.63$ & 37.83 & $0.000^{* *}$ \\
\hline $\mathrm{mh}$ & $3.18 \pm 0.24$ & $2.90 \pm 0.29$ & 29.73 & $0.000^{* *}$ \\
\hline $\mathrm{mPec}$ & $3.34 \pm 0.25$ & $3.07 \pm 0.32$ & 34.492 & $0.000^{* *}$ \\
\hline $\mathrm{mA}$ & $8.76 \pm 0.65$ & $7.99 \pm 1.03$ & 15.558 & $0.000^{* *}$ \\
\hline
\end{tabular}

Table 3. Discriminant analysis classification showing numbers and percentages of fish classified in groups from each locality.

\begin{tabular}{lccc}
\hline Locality & M'diq & Mehdia & Percent (\%) \\
M'diq & 66 & 18 & 100 \\
Mehdia & 39 & 80 & 100 \\
\hline
\end{tabular}




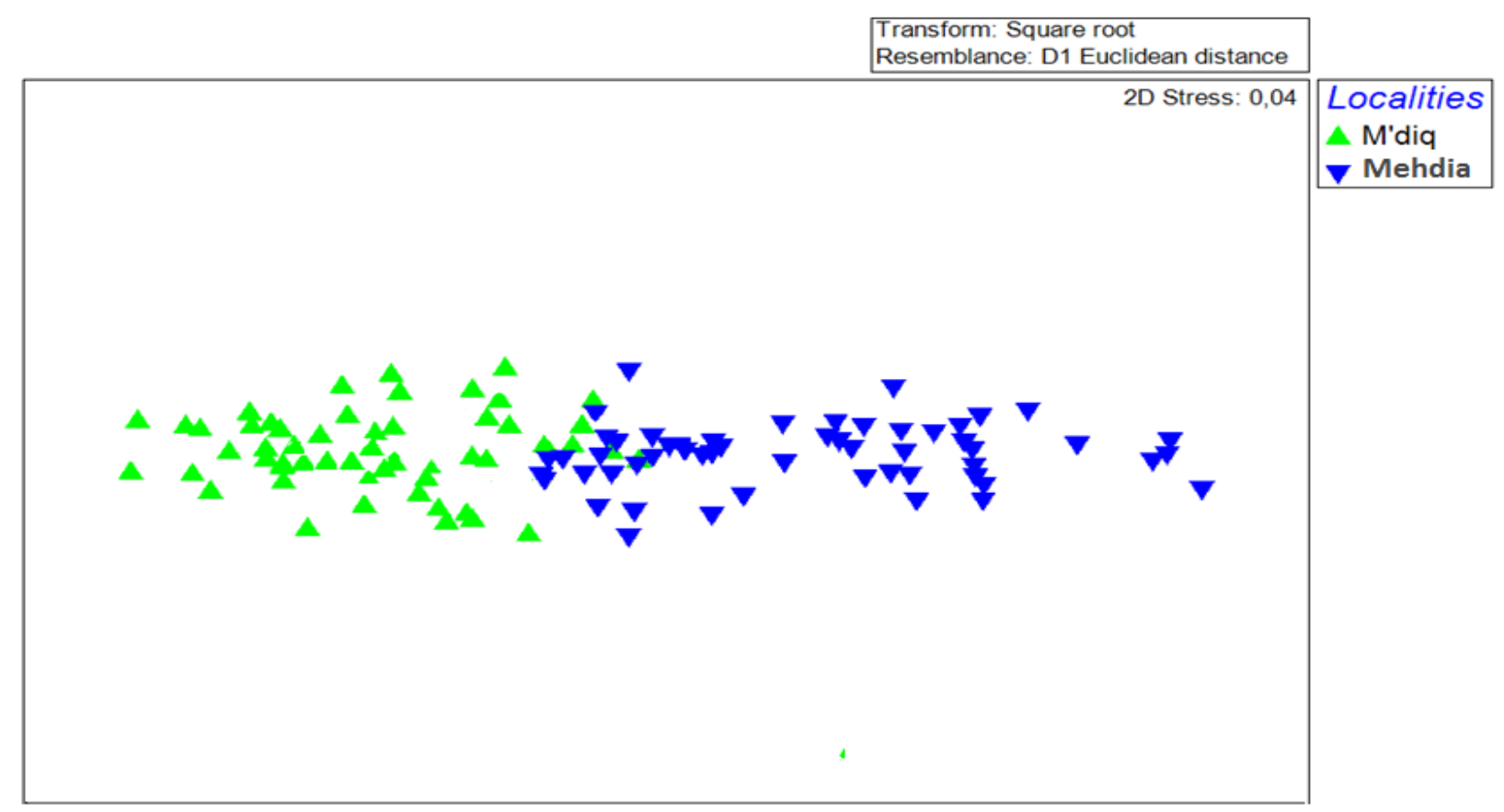

Figure 3. nMDS ordination of Bray-Curtis similarities computed on three significant measured variables of the two groups.

area have a wider and more elongated body than Mehdia specimens. According to Webb and Blake (1985), a more robust body is better adapted to better swimming performance.

Temperature and salinity may also have an effect on the morphometric characteristics of fish (Bektas and Belduz, 2009; Heino 2014). Indeed, temperature and salinity are higher in the Mehdia zone than in the M'diq zone. Head size is larger in samples from M'diq, which could be related to a varied diet (Hyndes et al., 1997; Delariva and Agostinho, 2001), as diet is an ecological parameter known to influence fish head morphology (Costa and Cataudella, 2007). Delariva and Agostinho, (2001) showed that head morphology and size are different in populations belonging to the same species but with a varied diet. In addition, snout length always depends on the availability, type and size of prey (Palma and Andrade, 2002) and consequently on the habitat (Turan et al., 2004). Thus, the variation of the latter reflects the distances of the prelengths of the dorsal, anal and pectoral fins, making these lengths discriminating.

\section{Conclusion}

Stock structure analysis is of primary importance in developing an optimal strategy for its management. Identifying intraspecific units or stocks of a species with unique morphological characteristics has now become more powerful and enables a better management of these subunits of species and ensures better management and conservation of the fishery resources. These results confirm the discriminating capacity of morphometric characteristics in the separation of two stocks of Engraulis encrasicolus between the two localities of M'diq and Mehdia, which could be used for the elaboration of new fishing management strategies for a better exploitation of the available resources.

\section{Ethical Statement}

The care and use of experimental animals, sampling and analysis techniques used in this work are consistent with the Moroccan Legislation Article 14, Section 3, Bill 122.22 and the Cartagena Protocol on Biosafety to the Convention on Biological Diversity promulgated by the royal decree "1.09.123".

\section{Funding Information}

Thanks are due to the project of TunisianMoroccan program for scientific cooperation $N^{\circ} 17 / \mathrm{TM}$ 23 for financial support to carry out this work.

\section{Author Contribution}

ME conducted the field and laboratory work as well as the writing of the first draft of the manuscript. FW supervise the work and MS helped in statistical analysis and assist in the laboratory work. AS, LB, LN and AY conduct and supervise the research project. All authors contributed on specific aspects.

\section{Conflict of Interest}

The authors declare that they have no known competing financial interests or personal relationships that could have appeared to influence the work reported on the paper. 


\section{Acknowledgements}

The authors are grateful to the Professors Ahmed Yahyaoui and Fatima Wariaghli, for providing necessary facilities. We would like to thank Mr. Mohammed El qendouci for assistance with the biological sampling. We would also like to especially acknowledge Editor-in-chief and referees for their constructive comments for the improvement of our paper.

\section{References}

Begg, G., Friedland, K.D. and Pearce, J.B. (1999). Stock Identification - its role in stock assessment and fisheries management. Fisheries Research Journal, 43, 1-8.

Bektas, Y.\&Belduz, A. O. (2009). Morphological Variation among Atlantic Horse Mackerel, Trachurus trachurus Populations from Turkish Coastal Waters. Journal of Animal and VeterinaryAdvances, 8 (3): 511-517.

Benazzouz, A. (2014). Upwelling côtier et effet de la dynamique océanique à méso-échelle sur la variabilité et la distribution planctonique dans le système d'upwelling du courant des canaries. Université Hassan II Casablanca-Mohammadia, pp 262.

Béné, C., Macfadyen, G., Allison, E.H. (2007). Increasing the contribution of small-scale fisheries to poverty alleviation and food security. FAO Fisheries Technical paper. No. 481. Rome, FAO.125p.

Cadrin, S.X. (2000). Advances in morphometric identification of fishery stocks. Review in fish biology and fisheries. 10, pp. 91-112.

Cadrin, S.X., Friedland, K.D. (1999). The utility of image processing techniques for morphometric analysis and stock identification. Fisherie. Ressource journal. 43, 129139.

Cavalcanti, M.J., Monteiro, L.R.P. Lopes (1999) Landmarkbased morphometric analysis in selected species of serranid fishes (Perciformes: Teleostei) Zoological Studies 38, pp. 287-294.

Costa, C., \&Cataudella, S. (2007). Relationship between shape and trophic ecology of selected species of Sparids of the Carolace coastal lagoon (central Tyrrhenian Sea). Environmental Biology of Fishes. 78 (2): 115-123.

Delariva, R.L., \&Agostinho, A.A. (2001). Relationship between morphology and diets of six neotropicalloricariids. Journal of Fish Biology. 58,832-847.

Elliott, N.G., Haskard, K., Koslow, J.A. (1995). Morphometric analysis of orange roughly (Hoplostethusatianticus) off the continental slope of Southern Australia. Journal of fish biology. 46:202-220.

Erdoğan, Z., Turan, C., \& KOÇ, H.T. (2009). Morphologic and Allozyme Analyses of European anchovy (Engraulisencrasicolus (L. 1758)) in the Black, Marmara and Aegean Seas.Actaadriatica journal. 50(1): 77 - 90.

Everitt, B.S., \&Dunn, G. (1992). Applied Multivariate Data Analysis. Oxford University Press, NewYork. 304 pp.

Fisheries and Agriculture Organization of the United Nations (FAO) (2020). The State of World Fisheries and Aquaculture. Sustainability in action. Rome. https://doi.org/10.4060/ca9229en
Hyndes, G. A., Platell, M. E.\& Potter, I.C. (1997). Relationships between diet and body size, mouth morphology, habitat and movements of six sillaginid species in coastal waters: implications for resource partitioning, Marine Biology Journal 128: $585 \pm 598$.

ICES (International Council for the Exploration of the Sea) (1996). Report of the study group on stock identification protocols for finfish and shellfish stocks. ICES C.M. M1.

Ihssen, P.E., Bodre, H.F., Casselman, J.M., McGlade, J.M. Payne, N.R. and Utter, F.M. (1981). Stock identification: materials and methods. Canadian journal of fisheries and aquatic sciences. 38:1838-1855.

Kristoffersen, J. B. \& Magoulas, A. (2008). Population structure of anchovy Engraulis encrasicolus in the Mediterranean Sea inferred from multiple methods, Fisheries Research 91. 187-195.

Kritzer, J.P., and Liu, O.R. (2014). Fishery management strategies for addressing complex spatial structure in marine fish stocks identification methods. pp. 29-57 in CadrinSX, Kerr LA and Mariani S (Eds) Stock identification methods. San Diego, Elsevier.

Kumpf, H.E., Vaught, R.N., Grimes, C.B., Johnston, A.G. and Nakamura, E.L. (1987). Proceedings of the Stock Identification Workshop. NOAA Tech. Mem. NMFS-SEFC 199.

Langerhans, R.B., Layman, C.A., Langerhans, A.K.\&Dewitt, T.J. (2003). Habitat-associated morphological divergence in two Neotropical fish species, Biological Journal of the Linnean Society. 689-698.

La Violette, P.E. (1984). The advection of Submesoscale Thermal Features in the Alboran Sea Gyre. Journal of Physical Oceanography. 14(3): 550-565.

Moussa, M., \& Baccar, L. (2005). La lagune de Ghar El Melh : Diagnostic écologique et perspectives d'aménagement hydraulique Article "La lagune de Ghar El Melh: Diagnostic écologique et perspectives d'aménagement, (October 2016), 11-26.

Murta, A. G. (2000). Morphological variation of horse mackerel (Trachurus trachurus) in the Iberian and North African Atlantic: implications for stock identification, ICES Journal of Marine Science. 57: 1240-1248.

Palma, J., \& Andrade, J.P. (2002). Morphological study of Diplodussargus, Diploduspuntazzo, and Lithognathusmormyrus (Sparidae) in the Eastern Atlantic and Mediterranean Sea. Fisheries Research.57(1):1-8.

Pawson, M.G., and Jennings, S. (1996). A critique of methods for stock identification in marine capture fisheries. FisheriesRessource Journal. 25:203-217.

Rohlf, F. J., 2006: tpsDig2, Version 2. 1. State University of New York, Stony Brook. Available at: http://life.bio.sunysb.edu/morph (accessed on 29 September 2008).

Templeman, W. (1982). Stock discrimination in marine fishes. NAFO SCR Doc. 82/IX/79.

Turan, C., Erguden, D., Gurlek, M., Basusta, N., Turan, F. (2004). Morphometric structuring of the anchovy (Engraulisencrasicolus L.) in the black, Aegean and Northeastern Mediterranean seas. Turkish journal of veterinary and animal sciences. 28: 865-871. 